\title{
A comprehensive study of an economic order quantity model under fuzzy monsoon demand
}

\author{
SUJIT KUMAR DE ${ }^{1}$ and GOUR CHANDRA MAHATA ${ }^{2, *}$ \\ ${ }^{1}$ Department of Mathematics, Midnapore College (Autonomous), Paschim Medinipur 721101, India \\ ${ }^{2}$ Department of Mathematics, Sidho-Kanho-Birsha University, Ranchi Road, P.O.- Purulia Sainik School, \\ Purulia 723104, India \\ e-mail: skdemamo2008.com@gmail.com; gcmahata@yahoo.in; gourmahata@yahoo.co.in
}

MS received 26 July 2018; revised 11 October 2018; accepted 13 December 2018; published online 22 March 2019

\begin{abstract}
This article deals with a classical economic order quantity (EOQ) model under monsoon type fuzzy demand rate. It is nothing but the generalization of cloudy fuzzy model. We split the EOQ model into three parts according to the real-time fuzzy components of the demand rate. To defuzzify the model we develop an algorithm and the solution is obtained with the help of a nonlinear optimization technique that requires maximum aspiration level of the fuzzy membership of the objective function. Moreover, for comparative study we take numerical results of the crisp, general fuzzy and cloudy fuzzy model also. By this study we have shown that the decision maker might have to choose the monsoon type fuzzy environment all the time to control the proposed inventory. Moreover, sensitivity analysis and graphical illustrations are made to justify the new fuzzy approach.
\end{abstract}

Keywords. Inventory; fuzzy cloud; fuzzy monsoon; new solution algorithm; optimization.

\section{Introduction}

From the development of classical economic order quantity (EOQ) model, a lot of research works have been made on the inventory control system. Harris [1] studied the foundation in management problems in the field of Operations Research (OR). Nevertheless, owing to today's turbulent business environment, it is a common occurrence in the inventory planning that much relevant input data are either not known precisely, or cannot be found due to the lack of sufficient information [2]. For instance, due to various uncertainties of the market, the demand rate usually fluctuates from one cycle time to another. Moreover, for developing inventory models, a major difficulty faced by a decision maker (DM) is to forecast the annual demand. Through its process the characteristic of the EOQ model with backorders is studied by $\mathrm{Yao}$ and $\mathrm{Su}$ [3], $\mathrm{Wu}$ and Yao [4] and Björk [5], the model for imperfect quality is developed by Chang [6], Mahata and Goswami [7] and Sharifi et al [8], and that for deteriorating items is investigated by De et al $[9,10]$ and Mahata and Goswami [11].

In fuzzy decision-making problems, Bellman and Zadeh [12] first used the fuzzy programming technique to get the final decision. After this, numerous research techniques have been developed [13-16]. Authors like Chen and Chang [17] and Shekarian et al [18] discussed problems on defective products, and that for deteriorating items was

*For correspondence discussed by Pal et al [19]. Báez-Sáncheza et al [20] contributed genuine knowledge on polygonal fuzzy sets. Wang and Tang [21] investigated an economic production quantity (EPQ) model characterizing the set-up cost, the holding cost and the elapsed time as fuzzy variables. Zhang et al [22] assumed that the inventory set-up cost, holding cost and the other parameters are fuzzy variables. Hu et al [23] studied a model of fuzzy random variable where the elapsed time when the machine shifts from one state to another has been considered. Chakraborty et al [24] developed a deteriorating multi-item inventory model with price discount and variable demands via fuzzy logic under resource constraints. De [25] developed an EOQ model with natural idle time and wrongly measured demand rate. De and Sana [26] studied fuzzy order quantity inventory model with fuzzy shortage quantity and fuzzy promotional index. Kumar et al [27] developed a fuzzy model for ramp type demand and partial backlogging. De and Sana [28] developed a backlogging EOQ model considering a pentagonal fuzzy number and they used the centre of gravity method to defuzzify the model followed by phi coefficient test. Das et al [29] presented an integrated production inventory model in interactive fuzzy credit period for deteriorating items. Kumar and Goswami [30] proposed a fuzzy random EPQ model for imperfect quality items with possibility and necessity constraints. Recently, Mahata [31] investigated the learning effect on inventory modelling. Currently, Shekarian et al [32] wrote a comprehensive review of fuzzy inventory models. 
Alternatively, De and Beg [33, 34] introduced dense fuzzy approach to capture the degree of learning experiences in recent times. De and Mahata [35] extended the dense fuzzy set to cloudy fuzzy set and gave a new formula for defuzzification. Several attempts on the application of dense fuzzy rule were studied by De [36], Karmakar et al [37, 38] and Maity et al [39] extensively.

However, in the literature, several defuzzification methods have been found [40-44]. Cheng [45] discussed a new approach for ranking fuzzy numbers by distance method. Buckley and Chanas [46] discussed a fast method of ranking alternatives using fuzzy numbers. Ezatti and Saneifard [47] developed a method of continuous weighted quasi-arithmetic means. The extensive works on L-R fuzzy numbers analysed by Wang et al [48], Kumar et al [49] and Hajjari and Abbasbandy [50] left a mark in the subject based on deviation degree. Recently, Kumar [51] developed a defuzzification method of type-2 fuzzy variable pertaining to interval approximation. However, after the invention of cloudy fuzzy number [35] there are no such defuzzification methods available in the literature yet.

In this article, we consider a classical EOQ model where the demand rate follows monsoon type fuzzy uncertainty. A solution algorithm has been developed for its numerical illustration. Comparing the numerical result with that of the other related existing model we have shown the actual justification for the new approach. Sensitivity analysis and graphical illustration are made for its global acceptance.

\section{Preliminaries}

Here we shall discuss a few essential definitions and formulas, which have been used frequently for solving the proposed model.

\subsection{Normalized general triangular fuzzy number (NGTFN)}

Let $\tilde{D}$ be an NGTFN (shown in figure 1) having the form $\tilde{D}=\left(D_{1}, D_{2}, D_{3}\right)$. Then its membership function is defined by

$$
\mu(\tilde{D})=\left\{\begin{array}{llc}
0 & \text { if } & D\left\langle D_{1} \text { and } D\right\rangle D_{2}, \\
\frac{D-D_{1}}{D_{2}-D_{1}} & \text { if } & D_{1} \leq D \leq D_{2}, \\
\frac{D_{3}-D}{D_{3}-D_{2}} & \text { if } & D_{2} \leq D \leq D_{3}
\end{array}\right.
$$

Now, the left and right $\alpha$-cuts of $\mu(\tilde{D})$ are given by

$$
\begin{gathered}
L(\alpha)=D_{1}+\alpha\left(D_{2}-D_{1}\right) \quad \text { and } \\
R(\alpha)=D_{3}-\alpha\left(D_{3}-D_{2}\right) .
\end{gathered}
$$

Utilizing Yager's [52] index method, the index value of $\tilde{D}$ is given by

$$
I(\tilde{D})=\frac{D_{1}+2 D_{2}+D_{3}}{4} .
$$

\subsection{Cloudy normalized triangular fuzzy number [33, 35]}

Definition 1 Let $\tilde{A}$ be the fuzzy set whose components are the elements of $\mathcal{R} \times \mathcal{R}, \mathcal{R}$ being the set of real numbers with the membership grade satisfying the functional relation $\mu: \mathcal{R} \times \mathcal{R} \rightarrow[0,1]$. In particular, let one of the set $\mathcal{R}$ be taken from the time domain $T$. Thus we redefine the membership value $\mu$ such that $\mu: \mathcal{R} \times T \rightarrow[0,1]$. Now, as $t \rightarrow \infty$, if $\mu(x, t) \rightarrow 1$ for some $x \in \mathcal{R}$ and $t \in T$ then we call the set $\tilde{A}$ as a cloudy fuzzy number. If we consider the fuzzy number $\tilde{A}$ of the form $\tilde{A}=a_{1}, a_{2}, a_{3}$ then we call it "cloudy triangular fuzzy number". Now, if for all $t$ in $T$, $\mu(x, t)$ attains the highest membership degree 1 then we can express this fuzzy number as "cloudy normalized triangular fuzzy number" or CNTFN. A graphical representation of CNTFN is shown in figure 2.

\subsection{Distinction between cloudy fuzzy model and monsoon type fuzzy model}

Let us assume a triangular cloudy fuzzy number of the form

$$
\begin{gathered}
\tilde{A}=\underset{0<\rho, \quad \sigma<1}{\left\langle a\left(1-\frac{\rho}{1+t}\right), \quad a, \quad a\left(1+\frac{\sigma}{1+t}\right)\right\rangle, \quad \text { for }} \\
0<1
\end{gathered}
$$

where $t$ denotes the time variable and $a$ is a fixed number; $\rho$ and $\sigma$ are the left and right deviations (or fuzzy system parameters), respectively, of the fuzzy number $\tilde{A}$. If we take the time variable $t$ as the cycle time of the process, then the model associated with this process is called cloudy fuzzy model. If we consider the time variable $t$ as an ordinary time variable throughout any process, then the model associated with this process is called monsoon type fuzzy model. Basically, in cloudy fuzzy set the time variable $t$ is the ultimate goal (represents optimum cycle time) but it is not true for monsoon type fuzzy set. In cloud model, the fuzzification is done after the formation of crisp objective function; however, in monsoon model, fuzzy classification is done during the formulation of the fuzzy objective function. However, the defuzzification methods (they are based on a single objective for cloud model but multiple objectives for monsoon model) are different for the two fuzzy optimization problems.

Note that, by virtue, the cloud index of monsoon type fuzzy set is always higher than that of cloudy fuzzy set. Let $T_{1}$ and $T_{2}$ be the optimum cycle time in monsoon model and cloudy fuzzy model, respectively; then the cloud indexes (degrees of uncertainty) are 


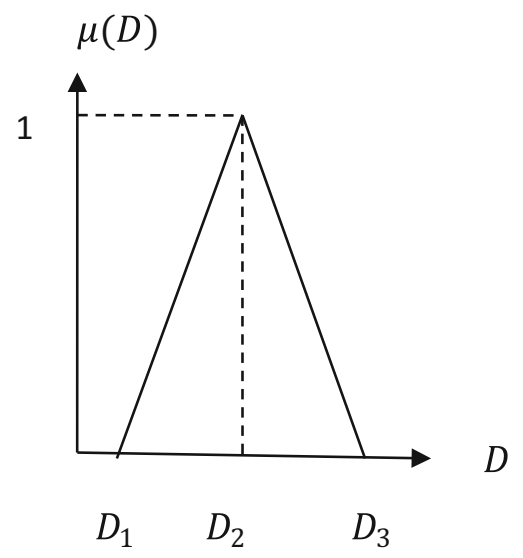

Figure 1. Membership function of NGTFN.

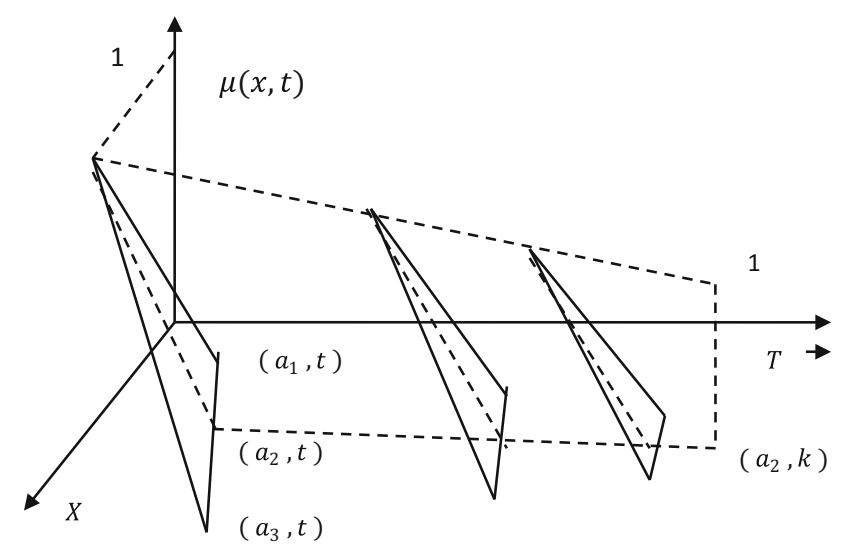

Figure 2. Membership function of CNTFN.

$$
\left\{\begin{array}{l}
\delta_{\text {monsoon }}=\frac{\log \left(1+\mathrm{T}_{1}\right)}{T_{1}}, \\
\delta_{\text {cloud }}=\frac{\log \left(1+\mathrm{T}_{2}\right)}{T_{2}}
\end{array}\right.
$$

Now, by definition, $\delta_{\text {monsoon }}>\delta_{\text {cloud }}$. Alternatively, since $T_{1}<T_{2}, \frac{\log \left(1+\mathrm{T}_{1}\right)}{T_{1}}>\frac{\log \left(1+\mathrm{T}_{2}\right)}{T_{2}}$ implies $\delta_{\text {monsoon }}>-$ $\delta_{\text {cloud }}$. In addition, we observe that the monsoon will converge to cloud if and only if $\delta_{\text {monsoon }} \rightarrow \delta_{\text {cloud }}$. In other words

$$
\delta_{\text {monsoon }}-\delta_{\text {cloud }}=\frac{\log \left(1+\mathrm{T}_{1}\right)}{T_{1}}-\frac{\log \left(1+\mathrm{T}_{2}\right)}{T_{2}}=\varepsilon \rightarrow 0 .
$$

Also, we see that $\lim _{t \rightarrow \infty} a\left(1-\frac{\rho}{1+t}\right) \rightarrow a$ and $\lim _{t \rightarrow \infty} a\left(1+\frac{\sigma}{1+t}\right) \rightarrow a$, hence $\tilde{A} \rightarrow\{a\}$.

\subsection{Bundle type/tunnel type curve}

Definition 2 Let $a_{i}$ be the fuzzy component associated with the $i$-tuple fuzzy number $\tilde{A}$. Then at $a_{i}, i \in N$ if the objective functions $z_{i}$ follow independent (non-intersecting but can take curvature all the time) curves $z_{1}, z_{2}, z_{3}, \ldots, z_{n}$ then we call such curves as bundle type curves. Moreover, if any one of them coincides with another or we are interested to study the situation between two independent curves then the curves along with their geometrical shape are known as tunnel type curves. Consider the case of triangular fuzzy number $\tilde{A}=a_{1}, a_{2}, a_{3}$; then the following situations may arise. Figure $3 \mathrm{a}-\mathrm{c}$ indicates the converging, diverging and natural tunnel type curves of the fuzzy objective functions with respect to the fuzzy set $\tilde{A}$.

\subsection{The conventional left fuzzy (L-fuzzy) number}

Let a fuzzy number $\tilde{b}$ have $U$ and $L$ as upper and lower bounds. Then we call this fuzzy number as the left fuzzy number if its membership function can be expressed in the following way (shown in figure 4):

$$
\mu_{\tilde{b}}(x)=\left\{\begin{array}{lll}
0 & \text { if } & x>U \\
\frac{U-x}{U-L} & \text { if } & L \leq x \leq U, \\
1 & \text { if } & x \leq L
\end{array}\right.
$$

\section{Assumptions and notations}

The following notations and assumptions are used to develop the model.

\section{Assumptions}

1. Replenishments are instantaneous.

2. The time horizon is infinite (weeks).

3. Shortages are not allowed.

\section{Notations}

$q$ the order quantity per cycle (a decision variable)

$d$ demand rate per week

$k \quad$ set-up cost per cycle (\$)

$h$ inventory holding cost per unit quantity per cycle (\$)

$c$ purchasing price of unit item (\$)

$t$ cycle time (weeks) (a decision variable)

$z$ average total cost of the inventory (\$) (a decision variable)

\subsection{Crisp mathematical model}

Let the inventory start with order quantity $q$ and be depleted at the constant demand rate $D$. Then after the cycle time $T$ it reaches zero. The costs associated with it are unit purchasing 
(a) Fuzzy element

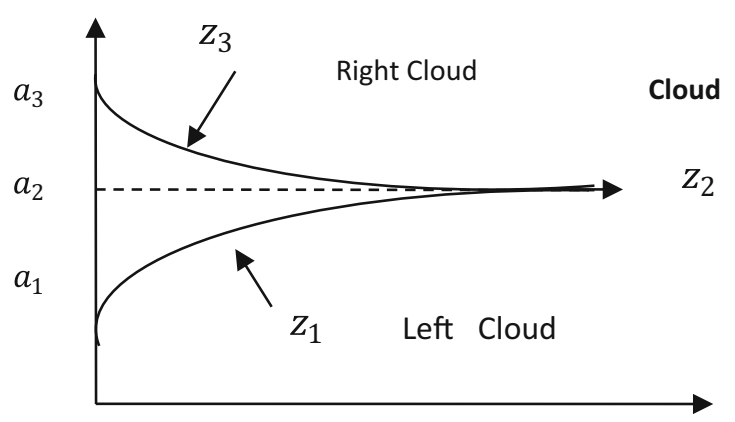

(b) Fuzzy element

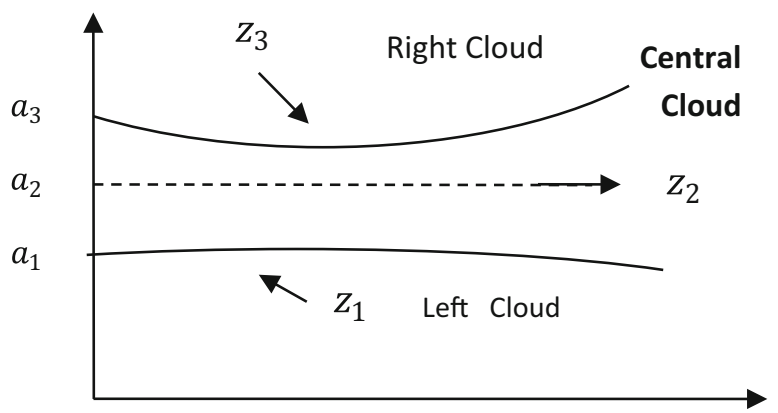

(c) Fuzzy element

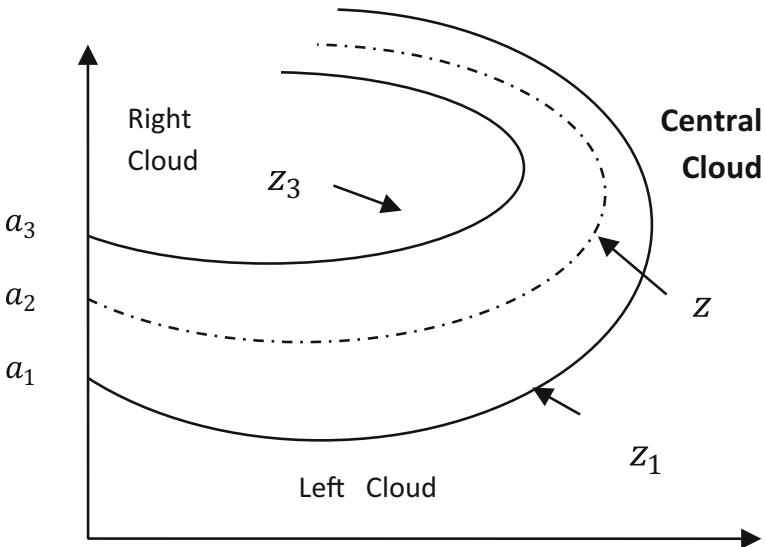

Figure 3. (a) Converging tunnel over time $t$. (b) Diverging tunnel over time $t$. (c) Natural tunnel over time $t$.

price $c$, unit holding cost $h$ and set-up cost $k$ only. Therefore, the inventory problem for average total cost is given as

$$
\left\{\begin{array}{l}
\operatorname{minimize} z=c D+\frac{k}{T}+\frac{h D T}{2} \\
\text { subject to } q=D T .
\end{array}\right.
$$

\subsection{Formulation of fuzzy monsoon mathematical model}

Let us assume that the demand rate of the proposed inventory model varies with the real-time fuzzy number

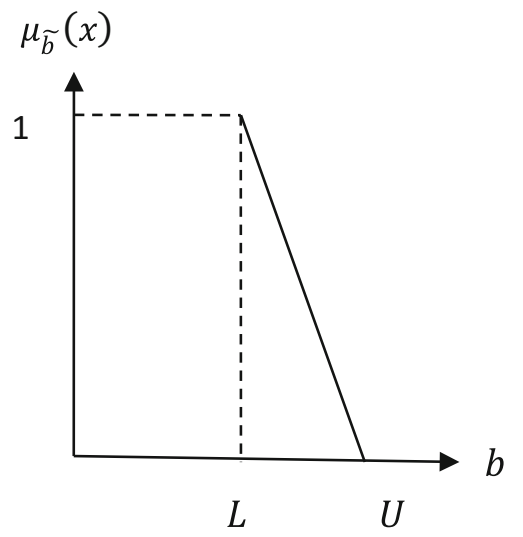

Figure 4. L-fuzzy membership function.

(fuzzy monsoon). We consider the fuzzy monsoon over the demand rate as

$\tilde{D}=d_{1}, d_{2}, d_{3}=\left\langle d\left(1-\frac{\rho}{1+t}\right), d, d\left(1+\frac{\sigma}{1+t}\right)\right\rangle, \quad$ for
$0<\rho, \quad \sigma<1$

where $\rho$ and $\sigma$ are left and right deviations, respectively, of the fuzzy set $\tilde{D}$. The left component of $\tilde{D}$ will generate the left cloud model, the middle component will create the crisp model (or central cloud model) and the right component will generate the right cloud model.

3.2a Left cloud model: We develop the objective function at the left fuzzy element (increasing function of $t$ ) of (6). Let $I_{1}(t)$ be the inventory level at time $t$; then the governing differential equation of the problem is given by

$$
\begin{cases}\frac{d I_{1}(t)}{d t}=-d\left(1-\frac{\rho}{1+t}\right), & 0 \leq t \leq T_{1} \\ \text { subject to } I_{1}(0)=q & \text { and } I_{1}\left(T_{1}\right)=0\end{cases}
$$

Solving (7), we get

$I_{1}(t)=d\left(T_{1}-t\right)-d \rho \log \left(\frac{1+T_{1}}{1+t}\right), \quad 0 \leq t \leq T_{1}$.

Order quantity $q=I_{1}(0)=d T_{1}-d \rho \log \left(1+T_{1}\right)$.

Purchasing cost $=c q=c d\left[T_{1}-\rho \log \left(1+T_{1}\right)\right]$.

$$
\begin{aligned}
\text { Holding cost } & =h \int_{0}^{T} I_{1}(t) d t \\
& =h d\left[\frac{T_{1}^{2}}{2}+\rho\left\{\log \left(1+T_{1}\right)-T_{1}\right\}\right] .
\end{aligned}
$$

Thus, total average inventory cost is given by 


$$
\begin{aligned}
z_{1}\left(T_{1}\right)= & \frac{\text { purchasing cost }+ \text { holding cost }+ \text { set }- \text { up cost }}{\text { cycle time }} \\
= & \frac{c d}{T_{1}}\left[T_{1}-\rho \log \left(1+T_{1}\right)\right]+\frac{k}{T_{1}}+\frac{h d}{T_{1}} \\
& {\left[\frac{T_{1}^{2}}{2}+\rho\left\{\log \left(1+T_{1}\right)-T_{1}\right\}\right] } \\
= & c d+\frac{h d T_{1}}{2}+\frac{k}{T_{1}}-\rho d\left[h+(c-h) \frac{\log \left(1+T_{1}\right)}{T_{1}}\right]
\end{aligned}
$$

Therefore, our problem is given as follows:

\section{3a. Solution algorithm:}

Step 1. Solve (13), (15) and (16) separately, get individual minimum of each objective and find their corresponding optimum decision variables.

Step 2. Find the minimum and maximum values among all the optimum objectives obtained in Step1. Find the minimum and maximum values of the decision variables also.

Step 3. Take a new objective from the average of all the objectives. To construct the appropriate membership functions of that objective function, order quantity and cycle time, assume $z^{\operatorname{Min}}=\operatorname{Min}\left\{\operatorname{Min}\left(z_{1}\right), \quad \operatorname{Min}\left(z_{2}\right)\right.$,

$$
\left\{\begin{array}{l}
\text { minimize } z_{1}\left(T_{1}\right)=c d+\frac{h d T_{1}}{2}+\frac{k}{T_{1}}-\rho d\left[h+(c-h) \frac{\log \left(1+T_{1}\right)}{T_{1}}\right] \\
\text { subject to } q=d T_{1}-d \rho \log \left(1+T_{1}\right)
\end{array}\right.
$$

3.2b Right cloud model: We develop the objective function at the right fuzzy element (decreasing function of $t$ ) stated in (6). Let $I_{3}(t)$ be the inventory level at time $t$; then the governing differential equation of the problem is

$$
\begin{cases}\frac{d I_{3}(t)}{d t}=-d\left(1+\frac{\sigma}{1+t}\right), & 0 \leq t \leq T_{3} \\ \text { subject to } I_{3}(0)=q & \text { and } I_{3}\left(T_{3}\right)=0 .\end{cases}
$$

Solving (14) and proceeding as earlier, we have

Now, for better understanding, the crisp problem can be redefined as follows.
$\left.\operatorname{Min}\left(z_{3}\right)\right\}$ and $z^{\operatorname{Max}}=\operatorname{Max}\left\{\operatorname{Min}\left(z_{1}\right), \operatorname{Min}\left(z_{2}\right), \operatorname{Min}\left(z_{3}\right)\right\}$; $q^{\operatorname{Min}}=\operatorname{Min}\left\{q_{1}^{*}, q_{2}^{*}, q_{3}^{*}\right\}, \quad q^{\operatorname{Max}}=\operatorname{Max}\left\{q_{1}^{*}, q_{2}^{*}, q_{3}^{*}\right\} ; T^{\operatorname{Min}}=$ $\operatorname{Min}\left\{T_{1}^{*}, T_{2}^{*}, T_{3}^{*}\right\}, T^{\operatorname{Max}}=\operatorname{Max}\left\{T_{1}^{*}, T_{2}^{*}, T_{3}^{*}\right\}$, respectively, as their corresponding upper and lower bounds.

Step 4. Construct the fuzzy membership functions of the objective function, order quantity and the cycle time as follows:

$$
\mu\left(z_{m}\right)=\left\{\begin{array}{lll}
0 & \text { if } & z_{m}>z^{\text {Max }} \\
\frac{z^{\text {Max }}-z_{m}}{z^{\text {Max }}-z^{\text {Min }}} & \text { if } & z^{\text {Min }} \leq z_{m} \leq z^{\text {Max }} \\
1 & \text { if } & z_{m} \leq z^{\text {Min }}
\end{array}\right.
$$

and

$$
\left\{\begin{array}{l}
\operatorname{minimize} z_{3}\left(T_{3}\right)=c d+\frac{h d T_{3}}{2}+\frac{k}{T_{3}}+\sigma d\left[h+(c-h) \frac{\log \left(1+T_{3}\right)}{T_{3}}\right] \\
\text { subject to } q=d\left[T_{3}+\sigma \log \left(1+T_{3}\right)\right]
\end{array}\right.
$$

3.2c Central cloud model: Here, we shall redefine the crisp problem stated as follows:

$$
\left\{\begin{array}{l}
\text { minimize } z_{2}=c d+\frac{k}{T_{2}}+\frac{h d T_{2}}{2} \\
\text { subject to } q=d T_{2}
\end{array}\right.
$$

Thus, the common problem of the fuzzy monsoon model is to find the decision variables $T$ and $q$ such that they would be able to minimize the objective functions stated in (13), (15) and (16) at a time.

\subsection{Solution procedure of the proposed model}

Here, we shall develop a solution algorithm to find a common solution of the problems stated in (13), (15) and (16).

$$
\left\{\begin{array}{l}
\gamma(T)=\left\{\begin{array}{lll}
0 & \text { if } & T>T^{\text {Max }} \\
\frac{T^{\text {Min }}-T}{T^{\text {Max }}-T^{M i n}} & \text { if } & T^{\text {Min }} \leq T \leq T^{\text {Max }} \\
1 & \text { if } & T \leq T^{\text {Min }}
\end{array}\right. \\
\vartheta(q)=\left\{\begin{array}{lll}
0 & \text { if } & q>q^{\text {Max }} \\
\frac{q^{\text {Min }}-q}{q^{\text {Max }}-q^{\text {Min }}} & \text { if } & q^{\text {Min }} \leq q \leq q^{\text {Max }} \\
1 & \text { if } & q \leq q^{\text {Min }} .
\end{array}\right.
\end{array}\right.
$$

Step 5. Using (17) and (18), formulate a nonlinear programming problem taking the aspiration level $\alpha$ with appropriate constraints. Maximize the aspiration level and get the result. In this proposed model our aim is to optimize the objective function $z_{m}=\frac{z_{1}+z_{2}+z_{3}}{3}$ where $z_{1}, z_{2}$ and $z_{3}$ are obtained from (13), (15) and (16), respectively. Using (13), (15) and (16)-(18), the nonlinear programming problem becomes 


$$
\left\{\begin{array}{l}
\text { maximize } \alpha \\
\text { subject to } z_{m}<z^{\text {Min }}+(1-\alpha)\left(z^{\text {Max }}-z^{\text {Min }}\right) \\
T<T^{\text {Min }}+(1-\alpha)\left(T^{\text {Max }}-T^{\text {Min }}\right) \\
q<q^{\text {Min }}+(1-\alpha)\left(q^{\text {Max }}-q^{\text {Min }}\right) \\
\text { where } z_{m}=\frac{z_{1}(T)+z_{2}(T)+z_{3}(T)}{3} \\
z_{1}(T)=z_{2}(T)-\rho d\left[h+(c-h) \frac{\log (1+T)}{T}\right] \\
z_{2}(T)=c d+\frac{k}{T}+\frac{h d T}{2} \\
z_{3}(T)=z_{2}(T)+\sigma d\left[h+(c-h) \frac{\log (1+T)}{T}\right] .
\end{array}\right.
$$

Thus, the membership functions of the cloudy fuzzy objective and its corresponding order quantity are given as

\subsection{Cloudy fuzzy model [33, 35]}

We rewrite the crisp problem (5) as $D=\frac{z-\frac{k}{T}}{c+\frac{h T}{2}}=\frac{q}{T}$. Now, the membership function of the demand rate is given as

$$
\begin{aligned}
& \mu(D, T)=
\end{aligned}
$$

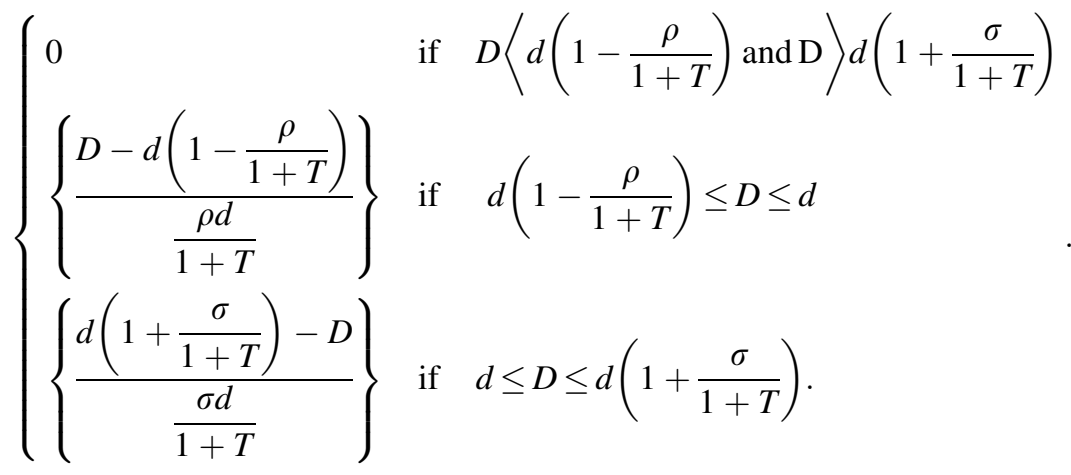

and

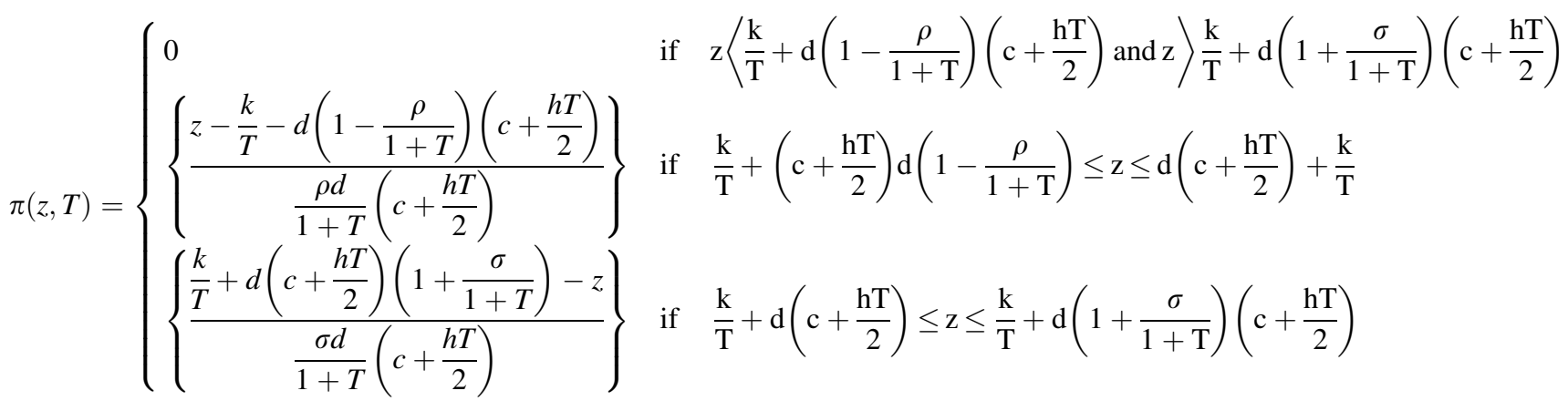




$$
w(q, T)= \begin{cases}0 & \text { if } \quad q\left\langle d T\left(1-\frac{\rho}{1+T}\right) \text { and } \mathrm{q}\right\rangle d T\left(1+\frac{\sigma}{1+T}\right) \\ \left\{\frac{q-d T\left(1-\frac{\rho}{1+T}\right)}{\frac{\rho d T}{1+T}}\right\} & \text { if } \quad d T\left(1-\frac{\rho}{1+T}\right) \leq q \leq d T \\ \left\{\frac{d T\left(1+\frac{\sigma}{1+T}\right)-q}{\frac{\sigma d T}{1+T}}\right\} & \text { if } \quad d T \leq q \leq d T\left(1+\frac{\sigma}{1+T}\right)\end{cases}
$$

respectively, where $0<\rho, \sigma<1$ and $T$ is the inventory cycle time. Now, the $\alpha$ cuts of the membership function of the cloudy fuzzy objective and that of order quantity obtained from (21)-(22) are given by $\left[\frac{k}{T}+(c+\right.$ $\left.\frac{h T}{2}\right)\left\{d\left(1-\frac{\rho}{1+T}\right)+\frac{\rho d \alpha}{1+T}\right\}, \frac{k}{T}+\left(c+\frac{h T}{2}\right)\left\{d\left(1+\frac{\sigma}{1+T}\right)-\frac{\sigma d \alpha}{1+}\right.$ $T\}]$ and $\left[d T\left(1-\frac{\rho}{1+T}\right)+\frac{\rho d T \alpha}{1+T}, d T\left(1+\frac{\sigma}{1+T}\right)-\frac{\sigma T d \alpha}{1+T}\right]$, respectively; the index value of cloudy fuzzy objective is written as

$$
\begin{aligned}
I(z)= & \frac{1}{2 \tau} \int_{\epsilon}^{\tau} \int_{0}^{1}\left[\frac{k}{T}+\left(c+\frac{h T}{2}\right)\left\{d\left(1-\frac{\rho}{1+T}\right)+\frac{\rho d \alpha}{1+T}\right\}+\frac{k}{T}\right. \\
& \left.+\left(c+\frac{h T}{2}\right)\left\{d\left(1+\frac{\sigma}{1+T}\right)-\frac{\sigma d \alpha}{1+T}\right\}\right] d \alpha d T \\
= & \frac{1}{2 \tau} \int_{\epsilon}^{\tau}\left[\frac{2 k}{T}+\left(c+\frac{h T}{2}\right)\left\{d\left(2-\frac{\rho-\sigma}{1+T}\right)+\frac{(\rho-\sigma) d}{2(1+T)}\right\}\right] d T \\
= & \frac{k \log (\tau / \epsilon)}{\tau}+c d+\frac{h d \tau}{4}-\frac{3 c d(\rho-\sigma) \log (1+\tau)}{4 \tau}-\frac{h d(\rho-\sigma)}{8} \\
& \left\{1-\frac{\log (1+\tau)}{\tau}\right\}
\end{aligned}
$$

and that for order quantity as

$$
\begin{aligned}
I(q)= & \frac{1}{2 \tau} \int_{\epsilon}^{\tau} \int_{0}^{1}\left[d T\left(1-\frac{\rho}{1+T}\right)+\frac{\rho d T \alpha}{1+T}\right. \\
& \left.+d T\left(1+\frac{\sigma}{1+T}\right)-\frac{\sigma T d \alpha}{1+T}\right] d \alpha d T \\
= & \frac{d \tau}{2}-\frac{d(\rho-\sigma)}{4}\left\{1-\frac{\log (1+\tau)}{\tau}\right\} .
\end{aligned}
$$

\subsection{Implication of cloudy fuzzy and fuzzy monsoon in inventory process}

In this uncertain world, the concepts of various parameters involved in managerial decisions are changing in a rapid way. A few of them are fixed over time and the others are time dependent. We know that in any inventory process, for a particular region, the customers' needs and choices are almost the same and predictable. In fact, at the beginning of a newly opened shop the number of customers is totally unknown. As time progresses, customers' motives and needs become clear and visible over the managerial framework. On the basis of this, DM can decide whether the system requires a strategic change or not. This way, the DM would have observed how much customers accept and adopt this process. In cloudy fuzzy environment the DM gains experiences from one cycle to another. However, in fuzzy monsoon approach the DM gains experiences continuously from the very beginning of the opening of the inventory process and has the options to change his/her strategy (through some path of thinking) any time without compromising on the normal cycle time of the process itself. The learning process over cycle time is shown in figure 5 .

\subsection{Conceptual convergence of physical monsoon and fuzzy monsoon}

We know that, at the monsoon season, the sky is always covered by clouds and the clouds accumulate in more and more denser and deeper manner over time. Whenever the clouds get dense, the roads/paths of that particular place

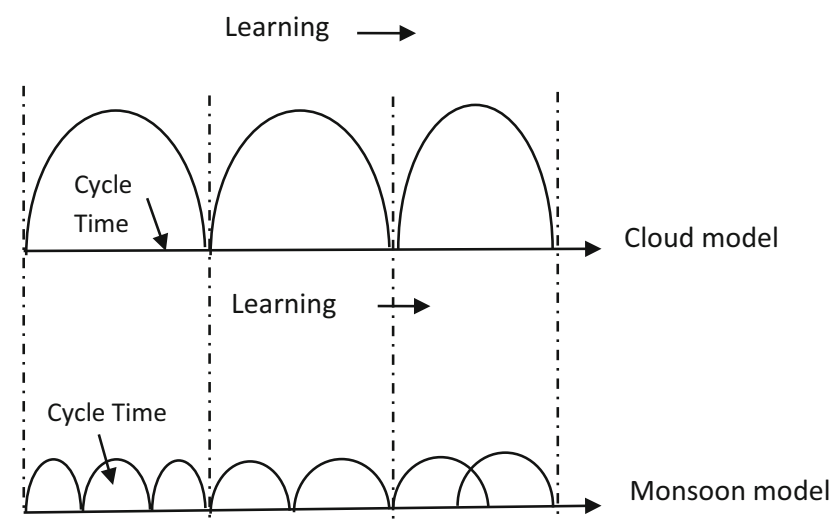

Figure 5. Learning process of cloud and monsoon type fuzzy model. 
become darkish and consequently the people begin to feel uneasy to walk across the road. However, as soon as the clouds get thinner, the path becomes visible and therefore people begin to walk freely. Similarly, in fuzzy monsoon, the solutions of the objective function are made by the DM with higher uncertainties than those of cloudy fuzzy model. A practical example is shown in appendix section to justify the proposed approach. The graphical illustrations are stated in figure $6 \mathrm{a}-\mathrm{c}$.

\section{Numerical illustrations}

Here we consider numerical solutions of all the objective functions with constraints stated in (13), (15) and (16) that are associated to monsoon type fuzzy model.

\subsection{Numerical example 1}

Let us consider $c=10, h=5, k=200, d=10, \sigma=0.2$, $\rho=0.8$ in Eqs. (13), (15) and (16). Then, we get the solution presented in table 1 .

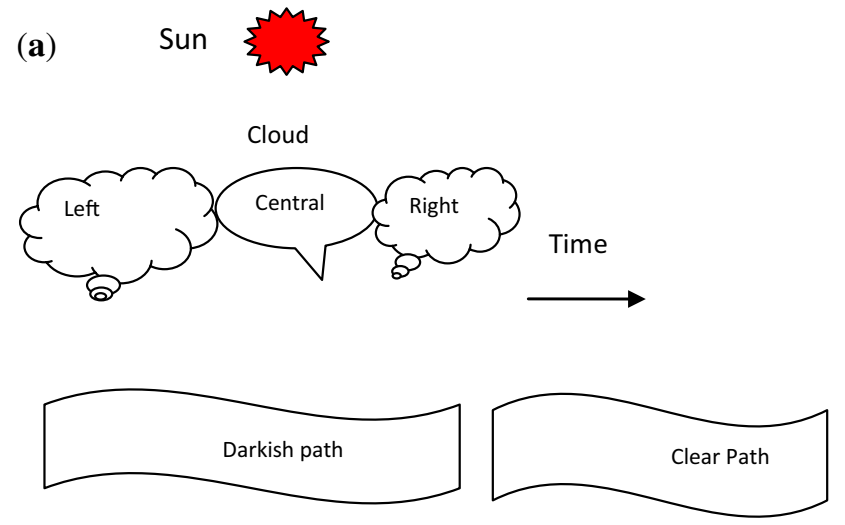

(b)

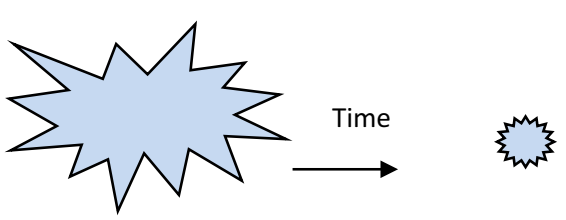

Major uncertainty Average uncertainty

(c)

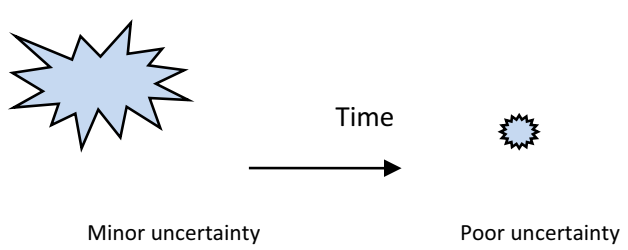

Figure 6. (a) Facts on physical monsoon. (b) Facts on fuzzy monsoon. (c) Facts on cloudy fuzzy environment.
Table 1. Optimal solution of the classical EOQ model.

\begin{tabular}{lccc}
\hline Decision variables & Optimize $z_{1}$ & Optimize $z_{2}$ & Optimize $z_{3}$ \\
\hline$T_{1 *}$ & 2.662 & & \\
$T_{2 *}$ & & 2.828 & \\
$T_{3^{*}}$ & & & 2.871 \\
$q_{1^{*}}$ & 16.236 & & \\
$q_{2^{*}}$ & & 28.084 & \\
$q_{3^{*}}$ & & & 31.421 \\
$z_{1 *}$ & 182.18 & & \\
$z_{2^{*}}$ & & 241.42 & 256.15 \\
$z_{3 *}$ & & & \\
\hline
\end{tabular}

Table 2. Optimal solution for the EOQ model.

\begin{tabular}{lcccc}
\hline & $\begin{array}{c}\text { Optimal } \\
\text { cycle time } \\
\text { (weeks) }\end{array}$ & $\begin{array}{c}\text { Order } \\
\text { quantity } \\
q^{*} \text { (units) }\end{array}$ & $\begin{array}{c}\text { Average } \\
\text { inventory } \\
\text { cost } z^{*}(\$)\end{array}$ & $\begin{array}{c}\text { Cloud } \\
\text { index }\end{array}$ \\
\hline $\begin{array}{l}\text { Crisp } \\
\begin{array}{c}\text { General } \\
\text { fuzzy }\end{array}\end{array}$ & 2.828 & 28.084 & 241.42 & - \\
$\begin{array}{c}\text { Cloudy } \\
\text { fuzzy }\end{array}$ & 7.794 & 28.635 & 245.68 & - \\
$\begin{array}{c}\text { Fuzzy } \\
\text { monsoon }\end{array}$ & 2.780 & 17.170 & 226.66 & 0.477 \\
\hline
\end{tabular}

Table 3. Solution of cloudy fuzzy and fuzzy monsoon EOQ model.

\begin{tabular}{|c|c|c|c|c|c|c|}
\hline \multirow{2}{*}{$\begin{array}{l}\text { Cycle time } \\
T \text { (weeks) }\end{array}$} & \multicolumn{2}{|c|}{ Cloudy fuzzy } & \multicolumn{2}{|c|}{ Crisp model } & \multicolumn{2}{|c|}{ Fuzzy monsoon } \\
\hline & $q_{*}$ & $z_{*}$ & $q_{*}$ & $z *$ & $q_{*}$ & $z_{*}$ \\
\hline 1 & 4.233 & 537.20 & 10.00 & 325.00 & 4.455 & 308.07 \\
\hline 2 & 8.873 & 372.64 & 20.00 & 250.00 & 11.211 & 234.51 \\
\hline 3 & 13.655 & 305.43 & 30.00 & 241.67 & 18.909 & 227.05 \\
\hline 4 & 18.506 & 271.55 & 40.00 & 250.00 & 27.125 & 235.98 \\
\hline 5 & 23.396 & 253.33 & 50.00 & 265.00 & 35.670 & 251.42 \\
\hline 6 & 28.311 & 243.81 & 60.00 & 283.33 & 44.433 & 270.09 \\
\hline 7 & 33.242 & 239.66 & 70.00 & 303.57 & 53.364 & 290.60 \\
\hline 8 & 38.187 & 239.08 & 80.00 & 325.00 & 62.422 & 312.25 \\
\hline 9 & 43.140 & 241.00 & 90.00 & 347.22 & 71.579 & 334.66 \\
\hline 10 & 48.099 & 244.75 & 100.00 & 370.00 & 80.817 & 357.60 \\
\hline
\end{tabular}

In table 1, we see that the bounds of the desired objective function are $(182.18,256.15)$, bounds of the optimum cycle time are $(2.662,2.871)$ and those of the order quantity are (16.236, 31.421). Therefore, utilizing these results in (19) we can construct the problem of fuzzy monsoon model. However, we obtain the solution of crisp problem (16), solution of general fuzzy problem of (16) [utilizing (2) and taking fuzzy demand rate as $\tilde{D}=<6,10,15>$ ] and that for cloudy fuzzy problem (23)-(24) taking $\epsilon=0.09$ and the outputs are shown in table 2 also. Table 3 shows 10 weeks comprehensive studies of the average inventory cost and their respective decision variable in cloudy fuzzy model, crisp model and monsoon type fuzzy model. 
Table 4. Sensitivity analysis of the fuzzy monsoon model.

\begin{tabular}{|c|c|c|c|c|c|c|c|}
\hline Parameters & $\begin{array}{c}\text { Change } \\
(\%)\end{array}$ & $\begin{array}{l}\text { Cycle time } T^{*} \\
\text { (weeks) }\end{array}$ & $\begin{array}{l}\text { Order quantity } \\
\qquad q^{*}\end{array}$ & $\begin{array}{c}\text { Average total cost } \\
z^{*}\end{array}$ & $\frac{\left(z^{*}-z_{*}\right)}{z_{*}} \times 100 \%$ & $\begin{array}{c}\text { Aspiration level } \\
\alpha^{*}\end{array}$ & $\begin{array}{l}\text { Cloud } \\
\text { index }\end{array}$ \\
\hline \multirow[t]{4}{*}{$c$} & +50 & 2.744 & 30.082 & 271.86 & 12.61 & 0.717 & 0.481 \\
\hline & +30 & 2.761 & 29.852 & 253.79 & 5.12 & 0.774 & 0.480 \\
\hline & -30 & 2.811 & 17.475 & 199.52 & -17.36 & 0.945 & 0.476 \\
\hline & -50 & 2.584 & 15.629 & 182.00 & -24.61 & 1.00 & 0.494 \\
\hline \multirow[t]{4}{*}{$h$} & +50 & 2.295 & 25.237 & 255.61 & 5.88 & 0.768 & 0.520 \\
\hline & +30 & 2.458 & 27.057 & 244.72 & 1.37 & 0.803 & 0.505 \\
\hline & -30 & 3.304 & 35.956 & 205.61 & -14.83 & 0.926 & 0.442 \\
\hline & -50 & 3.880 & 38.419 & 188.92 & -21.75 & 0.978 & 0.409 \\
\hline \multirow[t]{4}{*}{$d$} & +50 & 2.267 & 37.550 & 300.40 & 24.44 & 0.628 & 0.522 \\
\hline & +30 & 2.438 & 34.580 & 271.68 & 12.53 & 0.718 & 0.507 \\
\hline & -30 & 4.117 & 31.102 & 180.85 & -25.09 & 1.00 & 0.397 \\
\hline & -50 & 4.175 & 14.298 & 143.12 & -40.72 & 1.00 & 0.394 \\
\hline \multirow[t]{4}{*}{$k$} & +50 & 3.423 & 37.172 & 258.87 & 7.23 & 0.758 & 0.434 \\
\hline & +30 & 3.183 & 34.653 & 246.763 & 2.21 & 0.796 & 0.449 \\
\hline & -30 & 2.324 & 13.669 & 203.17 & -15.84 & 0.933 & 0.517 \\
\hline & -50 & 1.957 & 10.899 & 184.48 & -23.44 & 0.992 & 0.554 \\
\hline \multirow[t]{4}{*}{$\rho$} & +50 & 2.758 & 30.228 & 216.80 & -10.2 & 0.890 & 0.480 \\
\hline & +30 & 2.769 & 30.346 & 220.74 & -8.56 & 0.878 & 0.479 \\
\hline & -30 & 2.803 & 30.701 & 232.57 & -3.67 & 0.841 & 0.477 \\
\hline & -50 & 2.814 & 22.848 & 236.50 & -2.03 & 0.829 & 0.476 \\
\hline \multirow[t]{4}{*}{$\sigma$} & +50 & 2.793 & 17.265 & 229.12 & -5.09 & 0.852 & 0.477 \\
\hline & +30 & 2.790 & 17.582 & 228.14 & -5.50 & 0.855 & 0.478 \\
\hline & -30 & 2.782 & 29.602 & 225.18 & -6.72 & 0.864 & 0.478 \\
\hline & -50 & 2.780 & 17.425 & 224.20 & -7.13 & 0.867 & 0.478 \\
\hline
\end{tabular}

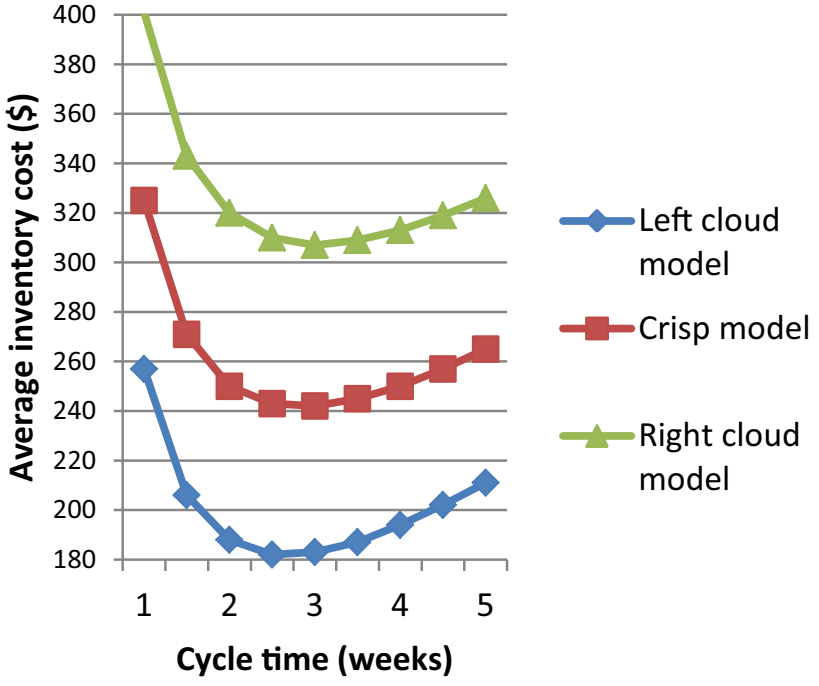

Figure 7. Total average cost vs. cycle time.

\subsection{Discussion on tables 2 and 3}

From table 2, we see that for the cases of crisp, general fuzzy and monsoon type fuzzy model the optimal solution exists near 3 weeks of cycle time and among them monsoon type model gets the lowest value than others. However, for the case of cloud model, the optimality reaches near 8

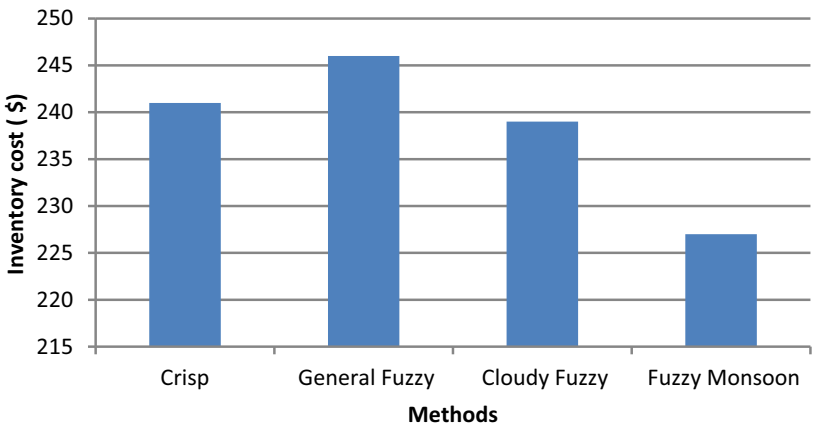

Figure 8. Optimum cost for fuzzy monsoon inventory.

weeks cycle time, giving the average inventory cost of $\$$ 238.95, which is $\$ 12.29$ more than that of monsoon model. Also, we see that the cloud index for cloud model is 0.281 but that for monsoon model is 0.477 exclusively. Moreover, table 3 reveals that for the case of 10 weeks extensive studies the cloud model gives optimum average inventory cost of $\$ 239.08$ at 8 weeks cycle time with respect to the order quantity of 38.187 units. However, at only 3 weeks cycle time, crisp, as well as monsoon, model gives optimum average inventory cost function in which the monsoon model assumes the lowest inventory cost value of the whole table values. It is also seen that since cloud index is directly related to cycle time, the solution in higher uncertainty 


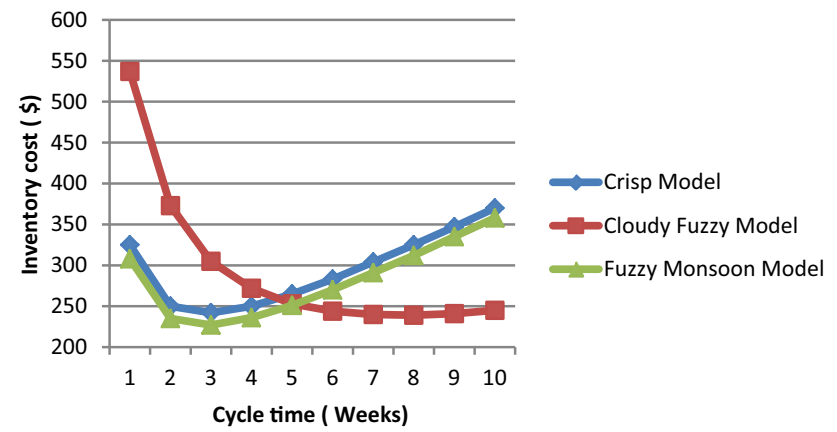

Figure 9. Cloudy fuzzy vs. fuzzy monsoon solution.

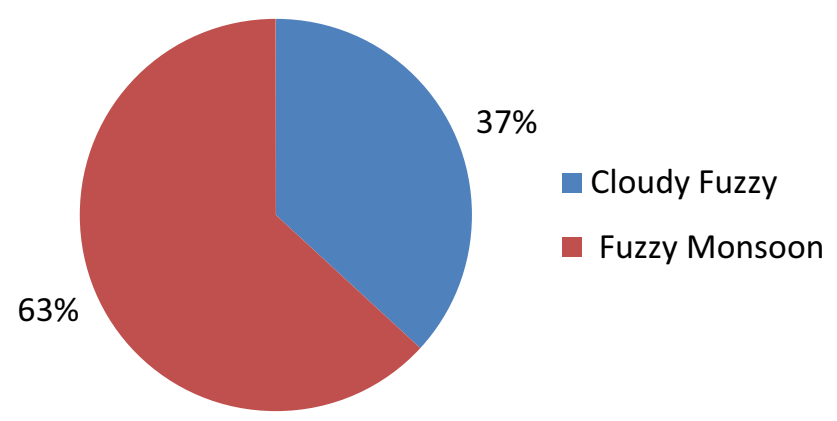

Figure 10. Measures of cloud index.

system assumes lesser inventory cost than lesser uncertainty systems.

\subsection{Sensitivity analysis}

Let us consider the sensitivity of each of the parameters $c$, $h, d, k, \rho, \sigma(-50 \%$ to $+50 \%)$ to study the effective variation of the monsoon model. The observations are listed in table 4 . From table 4 we see that the demand parameter $d$ is moderately sensitive and the corresponding inventory cost assumes minimum value with respect to the cycle time of 4.18 weeks (approximately) whenever a $-50 \%$ change is made keeping the cloud index as 0.394 only. The parameters $c, k$ and $h$ are also moderately sensitive for changes of $-30 \%$ to $-50 \%$ alone. The value of the cost function has average sensitivity for $+30 \%$ to $+50 \%$ changes also. Here, in almost all the cases, the cycle time assumes values within the range of 1.96-3.88 weeks and the range of average inventory cost is \$182.00-\$271.86 with respect to the range of order quantity of 15.629-37.172 units only. Again, the left and right fuzzy deviation parameters $\rho, \sigma$ are less sensitive for $-50 \%$ to $+50 \%$ changes. We also notice that the average cost function assumes lesser values throughout the changes keeping the cost value at \$216.80-\$236.50 with respect to order quantity within 17.265-30.701 units exclusively. However, if we go across the whole table, we see that the cloud index assumes maximum value of 0.554 with maximum aspiration level and it came from $-50 \%$ change of set-up cost $k$ only.

\section{Graphical illustrations of the model}

Here we discuss figures $7-10$ of the proposed model. Figure 7 shows the nature of cost function in monsoon type fuzzy model indicating the model optimum near 2.5-3.5 weeks cycle time. Figure 8 shows the values of the average inventory cost in crisp, general fuzzy, cloudy fuzzy and monsoon type fuzzy environment, where the monsoon type fuzzy model gets lower values than that of others. Figure 9 reveals that near 3 weeks cycle time the monsoon model gives finer result than others. It also reveals that, near 5 weeks cycle time, all curves assume closure values around a neighbourhood point. However, all the curves begin to diverge as the cycle time increases. Figure 10 shows the measures of cloud index in the monsoon type fuzzy environment.

\section{Conclusion}

Here we have studied the classical EOQ model in cloudy fuzzy environment. The model is studied in three different cases: (i) left cloud model, (ii) crisp model, (iii) right cloud model and (iv) monsoon model, which includes the models (i)-(iii). For the DM, the monsoon model is quite suitable as per the numerical study conducted in developing the model. Moreover, our findings support the basic code of business ethics "no risk no gain" or "high risk high gain". Alternatively, "high risk (uncertainty) low cost (high profit)" attitudes have been established because of the superiority of the monsoon (having higher cloud index) type fuzzy model with respect to the others (having less cloud index). Finally, the basic characteristics of this model are as follows:

(i) The components of each fuzzy parameter correspond to several increasing and decreasing functions of the time variable and their combinations also.

(ii) To get better defuzzified value of the fuzzy objective function it is essential to have closure of the different fuzzy objective functions at least once even if they diverge at all other times separately.

(iii) Fuzzification exclusively depends on real-time variable; beyond this, everything is crisp deterministic.

Incorporating some other algorithms for multi-objective functions in monsoon type fuzzy model, several new research works can be developed. 


\section{Acknowledgements}

The authors express sincere thanks to the editor and the anonymous reviewers for their valuable and constructive comments and suggestions, which led to a significant improvement of an earlier version of the manuscript.

\section{Appendix A}

\section{A practical example of the proposed model}

Suppose a salesman (DM) purchases (orders) goods after six days in a week. The amount of stock is decided according to weekly demand rate by the seller. Learning and gaining demand status of the first week(s) are used to order the items accordingly for the second week. Similarly, gaining the experience from the second week(s), he may change the amounts of order quantity accordingly for the next week and so on.

On the other hand, if the salesman wants to apply his/her learning experiences day-wise for the selling process, the he/she may shorten the length of cycle time accordingly. In this case the demand rate might vary in any two or three consecutive days, and hence the order quantity also. Thus the problem is as follows:

(i) Is it profitable if the DM replenishes his/her order quantities once after each and every cycle time, where the length of each cycle time does not vary in a non-random uncertain system?

(ii) Is it profitable if the DM replenishes his/her order quantities once after each and every cycle time, where the length of each cycle time varies from one cycle to another in a non-random uncertain system?

The answer is too much popular, because the basic aim of inventory management is to minimize system cost (or maximizing profit); hence, obviously the second case will give the minimum system cost and hence it is a part of monsoon type fuzzy model.

Since the basic aim of learning is to minimize inventory cost, obviously for the second case the average inventory cost will be minimum.

\section{References}

[1] Harris F 1915 Operations and cost. In: Factory Management Series. Chicago: A. W. Shaw Company

[2] Mahata G C and Mahata P 2011 Analysis of a fuzzy economic order quantity model for deteriorating items under retailer partial trade credit financing in a supply chain. Mathematical and Computer Modelling 53: 1621-1636

[3] Yao J S and Su J S 2000 Fuzzy inventory with backorder for fuzzy total demand based on interval-valued fuzzy set. European Journal of Operational Research 124: 390-408
[4] Wu K and Yao J S 2003 Fuzzy inventory with backorder for fuzzy order quantity and fuzzy shortage quantity. European Journal of Operational Research 150: 320-352

[5] Björk K M 2009 An analytical solution to a fuzzy economic order quantity problem. International Journal of Approximate Reasoning 50: 485-493

[6] Chang H C 2004 An application of fuzzy sets theory to the EOQ model with imperfect quality items. Computers \& Operations Research 31: 2079-2092

[7] Mahata G C and Goswami A 2007 An EOQ model for deteriorating items under trade credit financing in the fuzzy sense. Production Planning and Control 18: 681-692

[8] Sharifi E, Shabani S, Sobhanallahi M A and Mirzazadeh A 2015 A fuzzy economic order quantity model for items with imperfect quality and partial backordered shortage under screening errors. International Journal of Applied Decision Sciences 8: 109-126

[9] De S K, Kundu P K and Goswami A 2003 An Economic Production Quantity inventory model involving fuzzy demand rate and fuzzy deterioration rate. Journal of Applied Mathematics and Computing 12(1): 251-260

[10] De S K, Kundu P K and Goswami A 2008 Economic ordering policy of deteriorated items with shortage and fuzzy cost co-efficients for vendor and buyer. International Journal of Fuzzy Systems and Rough Systems 1(2): 69-76

[11] Mahata G C and Goswami A 2013 Fuzzy inventory models for items with imperfect quality and shortage backordering under crisp and fuzzy decision variables. Computers \& Industrial Engineering 64: 190-199

[12] Bellman R E and Zadeh L A 1970 Decision making in a fuzzy environment. Management Science 17: B141-B164

[13] Park K 1987 Fuzzy-set theoretic interpretation of economic order quantity. IEEE Transactions on Systems, Man and Cybernetics 17: 1082-1084

[14] Guiffrida A L 2009 Fuzzy inventory models. In: Inventory Management: Non-Classical Views, p. 173

[15] Shekarian E, Glock C H, Amiri S M P and Schwindl K 2014 Optimal manufacturing lot size for a single-stage production system with rework in a fuzzy environment. Journal of Intelligent and Fuzzy Systems 27(6): 3067-3080

[16] Shekarian E, Olugu E U, Abdul-Rashid S H and Kazemi N 2016 An economic order quantity model considering different holding costs for imperfect quality items subject to fuzziness and learning. Journal of Intelligent and Fuzzy Systems 30(5): 2985-2997

[17] Chen S H and Chang S M 2008 Optimization of fuzzy production inventory model with unrepairable defective products. International Journal of Production Economics 113: 887-894

[18] Shekarian E, Olugu E U, Abdul-Rashid S H and Bottani E 2016 A fuzzy reverse logistics inventory system integrating economic order/production quantity models. International Journal of Fuzzy Systems, https://doi.org/10.1007/s40815015-0129-x

[19] Pal S, Mahapatra G and Samanta G 2014 An EPQ model of ramp type demand with Weibull deterioration under inflation and finite horizon in crisp and fuzzy environment. International Journal of Production Economics 156: 159-166

[20] Báez-Sáncheza A D, Morettib A C and Rojas-Medarc M A 2012 On polygonal fuzzy sets and numbers. Fuzzy Sets and Systems 209: 54-65 
[21] Wang X and Tang W 2009 Optimal production run length in deteriorating production processes with fuzzy elapsed time. Computers and Industrial Engineering 56(4): 1627-1632

[22] Zhang C, Zhao R and Tang W 2009 Optimal run lengths in deteriorating production processes in random fuzzy environments. Computers and Industrial Engineering 57(3): 941-948

[23] Hu J S, Zheng H, Guo C Y and Ji Y P 2010 Optimal production run length with imperfect production processes and backorder in fuzzy random environment Computers and Industrial Engineering 59(1): 9-15

[24] Chakraborty N, Mondal S and Maiti M 2013 A deteriorating multi-item inventory model with price discount and variable demands via fuzzy logic under resource constraints. Computers \& Industrial Engineering 66(4): 976-987

[25] De S K 2013 EOQ model with natural idle time and wrongly measured demand rate. International Journal of Inventory Control and Management 3(1-2): 329-354

[26] De S K and Sana S S 2013 Fuzzy order quantity inventory model with fuzzy shortage quantity and fuzzy promotional index. Economic Modelling 31: 351-358

[27] Kumar R S, De S K and Goswami A 2012 Fuzzy EOQ models with ramp type demand rate, partial backlogging and time dependent deterioration rate. International Journal of Mathematics in Operational Research 4: 473-502

[28] De S K and Sana S S 2015 An EOQ model with backlogging. International Journal of Management Sciences and Engineering Management, https://doi.org/10.1080/17509653.2014.995736

[29] Das B C, Das B and Mondal S K 2015 An integrated production inventory model under interactive fuzzy credit period for deteriorating item with several markets. Applied Soft Computing 28: 453-465

[30] Kumar R S and Goswami A 2015 A fuzzy random EPQ model for imperfect quality items with possibility and necessity constraints. Applied Soft Computing 34: 838-850

[31] Mahata G C 2017 A production-inventory model with imperfect production process and partial backlogging under learning considerations in fuzzy random environments. Journal of Intelligent Manufacturing 28: 883-897

[32] Shekarian E, Kazemi N, Hanim Abdul-Rashid S H and Olugu E U 2017 Fuzzy inventory models: a comprehensive review. Applied Soft Computing 55: 588-621

[33] De S K and Beg I 2016 Triangular dense fuzzy sets and new defuzzification methods. Journal of Intelligent and Fuzzy Systems 31(1): 467-476

[34] De S K and Beg I 2016 Triangular dense fuzzy neutrosophic sets. Neutrosophic Sets and Systems 13: 24-37

[35] De S K and Mahata G C 2017 Decision of a fuzzy inventory with fuzzy backorder model under cloudy fuzzy demand rate. International Journal of Applied and Computational Mathematics 3(3): 2593-2609
[36] De S K 2017 Triangular dense fuzzy lock set. Soft Computing, https://doi.org/10.1007/s00500-017-2726-0

[37] Karmakar S, De S K and Goswami A 2017 A pollution sensitive dense fuzzy economic production quantity model with cycle time dependent production rate. Journal of Cleaner Production 154: 139-150

[38] Karmakar S, De S K and Goswami A 2018 A pollution sensitive remanufacturing model with waste items: triangular dense fuzzy lock set approach. Journal of Cleaner Production, https://doi.org/10.1016/j.jclepro.2018.03.161

[39] Maity S, De S K and Pal M 2018 Two decision makers' single decision over a back order EOQ model with dense fuzzy demand rate. Finance and Market 3: 1-11

[40] Chu T and Tsao C 2002 Ranking fuzzy numbers with an area between the centroid point and original point. Computational Mathematics and Applications 43: 111-117

[41] Ramli N and Mohamad D 2009 A comparative analysis of centroid methods in ranking fuzzy numbers. European Journal of Scientific Research 28(3): 492-501

[42] Allahviranloo T and Saneifard R 2012 Defuzzification method for ranking fuzzy numbers based on center of gravity. Iranian Journal of Fuzzy Systems 9(6): 57-67

[43] Ezzati R, Allahviranloo T, Khezerloo S and Khezerloo M 2012 An approach for ranking of fuzzy numbers. Expert Systems with Applications 39: 690-695

[44] Deng H 2014 Comparing and ranking fuzzy numbers using ideal solutions. Applied Mathematical Modelling 38: 1638-1646

[45] Cheng C H 1998 A new approach for ranking fuzzy numbers by distance method. Fuzzy Sets and Systems 95: 307-317

[46] Buckley J J and Chanas S 1989 A fast method of ranking alternatives using fuzzy numbers. Fuzzy Sets and Systems 30: 337-339

[47] Ezatti R and Saneifard R 2010 A new approach for ranking of fuzzy numbers with continuous weighted quasi-arithmetic means. Mathematical Sciences 4: 143-158

[48] Wang Z X, Liu Y J, Fan Z P and Feng B 2009 Ranking L-R fuzzy number based on deviation degree. Information Sciences 179: 2070-2077

[49] Kumar A, Singh P, Kaur P and Kaur A 2011 A new approach for ranking of L-R type generalized fuzzy numbers. Expert Systems with Applications 38: 10906-10910

[50] Hajjari T and Abbasbandy S 2011 A note on "The revised method of ranking LR fuzzy number based on deviation degree". Expert Systems with Applications 39: 13491-13492

[51] Kumar R S 2018 Modelling a type-2 fuzzy inventory system considering items with imperfect quality ad shortage backlogging. Sadhana 43: 163-175

[52] Yager R 1981 A procedure for ordering fuzzy subsets of the unit interval. Information Sciences 24(2): 143-161 